\title{
LA TESIS, UNA INVENCIÓN MUSICAL \\ TRABAJO FINAL EN MÚSICA POPULAR, VACILACIONES Y CERTEZAS
}

\section{THE THESIS, A MUSICAL INVENTION \\ FINAL WORK IN POPULAR MUSIC, VACILLATIONS AND CERTAINTIES}

\author{
Julio Schinca \\ julioschinca2001@yahoo.com.ar \\ Producción y análisis musical V. Facultad de Bellas Artes. Universidad Nacional de La Plata. Argentina
}

Recibido: 5/12/2017 | Aceptado: 10/3/2018

\section{RESUMEN}

Este artículo presenta una reflexión en torno a la realización de los trabajos de tesis en la cátedra Producción y Análisis Musical V, de la carrera de Música Popular de la Facultad de Bellas Artes (FBA) de la Universidad Nacional de La Plata (UNLP). Las preguntas, incertezas e inquietudes de muchos de los alumnos que transitan este último tramo representan el insumo esencial que nutre estas líneas y para ellos están dirigidas. La intención no es ofrecer un método infalible que allane el camino y resuelva la tarea, sino reflejar el marco pedagógico y los conceptos centrales de la cátedra en cuanto pistas que orienten el proyecto de cada uno de los estudiantes y se materialice en su realización final.

PALABRAS CLAVE

Tesis; preguntas; inquietudes; realización

\section{ABSTRACT}

This paper presents a reflection on the realization of thesis projects in the context of Musical Production and Analysis $V$, a subject of the Popular Musical degree course at the Faculty of Fine Arts (FBA), National University of La Plata (UNLP). The essential income for these lines are the questions, uncertainties and concerns from many of the students that took this advanced course. They are the target readers of these lines. The aim is not to provide a path-clearing or task-finishing method but to show our pedagogical framework and the course's central concepts in order to give clues for the materialization of the students' projects.

\section{KEYWORDS}

Thesis; questions; uncertainties; realization 
«Debajo de lo suave crepita la sospecha.

En estas manos.»

Juan Gelman (2001)

¿Cómo se hace una Tesis? ¿Por dónde comenzar? ¿Cómo elegir un tema? ¿Cómo recortarlo? ¿Cómo se organiza la información? ¿Qué representa realizar una Tesis en la carrera de Música Popular?

Estos interrogantes y muchos otros conforman el repertorio inicial de los alumnos que comienzan a cursar Producción y Análisis Musical V, la cátedra donde realizan su trabajo final de Licenciatura de la carrera de Música Popular en la Facultad de Bellas Artes (FBA) de la Universidad Nacional de La Plata (UNLP). En cada caso, la fuerza de las preguntas impulsa las búsquedas y abre camino a la exploración. Este breve artículo no pretende resolver las respuestas definitivas, sino ofrecer algunas de las ideas fundamentales que configuran el marco para que las Tesis sean realizadas.

si bien existe una profusa cantidad de textos que abordan esta problemática y que brindan consejos y soluciones parciales para evitar sortear las dificultades comunes, en ningún caso son específicos del campo del arte. Por lo general, sus aportes provienen de la investigación en ciencias duras o sociales, lo que representa el primer problema a resolver. Muchas veces se produce una traslación de supuestos que plantean los estudiantes con criterios de trabajo investigativo que son propios de otras áreas de conocimiento y no se ajustan a las particularidades que precisa la música. Por lo tanto, lo primero que establecemos es el criterio metodológico, que se relaciona con lo que Juan Samaja (2006) propone: «Es, pues, en el terreno de las imágenes, las abducciones y las analogías de la experiencia de donde emergen las hipótesis» (p.11) y agrega:

[...] la inducción no es la única forma de invertir la deducción para dar lugar a nuevas síntesis cognoscitivas. El propio Aristóteles reconoció los límites de

la inducción por enumeración de casos, e identificó la existencia de otra vía para el establecimiento de los principios de la ciencia: lo que él llamó intuición formal (p. 10).

Esta última afirmación sostiene que siempre partimos de una sospecha o priori sobre el objeto de estudio, cuya dinámica reduce la cantidad de posibles explicaciones a un rango acotado. Más aún, «el análisis nos ayuda a descubrir lo que ya sabíamos sin habernos dado cuenta; saca a la luz la parte más o menos inconsciente de nuestra experiencia de escucha», señala el pianista Charles Rosen (Etkin \& Villanueva, 2013, p. 7). Asimismo, la sutileza de las imágenes sonoras a veces impone abrevar en metáforas cuya ambigua opacidad no logra arribar a sentencias mecanicistas o teleológicas. 
Por eso, orientamos a no buscar verdades terminadas ni sistematizaciones finales, tampoco métodos infalibles ni hallazgos originales nunca pensados por otros. En consecuencia, orientamos estrategias y líneas posibles de trabajo, pero no sugerimos metodologías con fundamentos empiristas, inductivistas o cuantitativos por sostener que los fenómenos artísticos en la contemporaneidad configuran una complejidad que roza el orden de lo indecible con propiedades poéticas y múltiples interpretaciones. Esa es la zona que nos resulta más interesante. Parafraseando al gran poeta Juan Gelman (2001), valoramos la sospecha que habita debajo de lo suavemente cotidiano, la sospecha que posibilite la construcción de un sentido personal y poético a partir de las propias manos de los alumnos (manos que piensan), en una praxis que profundice el conocimiento musical y artístico.

Nuestra propuesta se orienta a la búsqueda de posicionamientos propios que definan una mirada política sobre el objeto de estudio musical y que construyan aproximaciones superadoras en diálogo con marcos teóricos que, enhebrados en una trama argumentativa, arriben a conclusiones que puedan ofrecer un aporte a la Música Popular (desde lo artístico o desde la enseñanza). Cabe aclarar que la noción de lo político la tomamos como expresión de una posición determinada o de estrategias para la vida. Rodolfo Kusch [1976] (2007) afirma que «si la cultura es estrategia para vivir en un lugar y en un tiempo entonces también es política» (p. 105). Por eso nos detenemos en reconocer la voz propia de cada tesista, en advertir qué es lo que quiere hacer, cuál es su propósito, cómo ajustar y nutrir con materiales y autores su propio punto de vista. A este aspecto dedicamos la totalidad de nuestros esfuerzos como docentes.

\section{DANDO VUELTAS AL TEMA}

Encontrar el tema del trabajo - en los casos que aún no lo saben- presenta el desafío inicial. Para ello, invitamos a los alumnos a reflexionar y bucear dentro de su propia trayectoria de formación musical y profesional para detectar aquello que les interesa y apasiona. Esta es una condición fundamental: que lo elegido tenga el encontomiento necesario como para acrecentar y sostener la curiosidad a lo largo de todo el proceso investigativo, que probablemente dure entre doce y dieciocho meses.

Hace ya algunos años, en una conversación que mantuve con el maestro Mariano Etkin (en Schinca, 2013), él decía: «Musicalmente uno siempre tiene dos, tres o cuatro cosas que se configuran en obsesiones a lo largo de su vida» (s/p). Son esos temas que vuelven a reaparecer una y otra vez en cada obra, en cada texto escrito. En algunos pueden ser los problemas del ritmo, del timbre, del espacio musical, de un instrumento. En otros, cuestiones ligadas a lo identitario, lo genérico, lo interdisciplinario o al contexto de producción. Lo importante es darse cuenta, estar atentos a detectar cuáles 
son los indicios que convocan regularmente nuestro interés sobre algo. A lo largo de las clases sugerimos diferentes estrategias de búsqueda para estimular ese descubrimiento que, por lo general, están dirigidas a explorar en lo más próximo. Por ejemplo, en los gustos y en las prácticas musicales habituales, en cuestiones que hayan resultado interesantes durante el trayecto de la carrera pero que no fueron profundizadas oportunamente, en géneros, contextos, elementos específicos de la música como el ritmo, el timbre, recursos interpretativos, etcétera.

En este sentido, pensamos que no hay temas pequeños o desdeñables para su tratamiento. Con relación a esto, Umberto Eco [1977] (2016) señala: «No es tan importante el tema de la tesis como la experiencia de trabajo que comporta. [...] trabajando bien se sacan conclusiones útiles incluso de un tema aparentemente remoto o periférico» (pp. 22-23). Cualquier fenómeno o cuestión musical que se elija puede ser una oportunidad para estudiar a fondo características, problemáticas y contextos, y para poner de relieve el conocimiento que comporta.

Llegados a este punto, es importante advertir que no hay un único formato de Tesis. En general sugerimos que, si el eje temático está puesto en la producción/composición de música, ésta vaya acompañada por una reflexión argumentativa escrita que enmarque y contextualice el producto artístico. Según el caso, si el trabajo es de orden más teórico, alentamos -si corresponde- que también haya una presentación musical. Esta relación dialéctica entre música y palabras se basa en la convicción de que «la música es experiencia, es tiempo y espacio materializado en el devenir de los sonidos, en la delimitación de su propia forma. Al producirla -tocarla, cantarla- estamos en la música de una manera vital-experiencial, estamos siendo con ella» (Benassi \& Schinca, 2017, p. 2).

Esa forma particular de estar siendo en la música es una experiencia intransferible del orden de lo perceptual-sonoro, que no son palabras o, como dice Daniel Belinche (2017), «la música no se puede contar» (p. 15). En ese quiebre entre las imágenes musicales y el mundo de las palabras reside el conocimiento que requiere ser explicado. La intensidad del esfuerzo reflexivo que impulsa el riesgo de aproximación a eso que no tiene palabras - porque es música - se convierte en el nudo central para resolver, el hiato para explorar. Muchas veces surge la necesidad de proponer nuevas formas de nombrar o de categorizar aquello que se quiere explicitar. Enfatizamos el hecho explicativo porque entendemos que la capacidad de hacer visible el conocimiento artístico de la música, con sus prácticas de producción, investigación y enseñanza es una función indelegable como egresados de la universidad pública.

Asimismo, insistimos en que no hay un formato preestablecido de Tesis; la única premisa es que el punto de partida sea siempre desde la música. Su presencia en la muestra final completa el sentido de lo investigado y expuesto, y aumenta sus atributos metafóricos. No hay manera de suplirla. Allí es donde todo lo trabajado cierra, se anuda, se sujeta, se proyecta, se amplía. 


\section{HACIA LA MASIVIDAD}

En la discusión sobre si el arte debe o no ser comercial y masivo/ popular, o sobre si hay o no arte en las producciones masivas, tenemos posiciones tomadas: pensamos que hay arte en lo masivo/popular, ya que la masividad es un rasgo de nuestra época en la que la tecnología digital posibilita una ubicuidad antes inusitada y ha modificado, incluso, los modos de producción artística. Claudia Kozak (2008) define dicha ubicuidad como «una propiedad del espacio pero en directa relación con el tiempo: estar al mismo tiempo en todo lugar» (p. 188). Otro autor asegura que «en la actualidad no se puede concebir la música popular sin pensar en la tecnología, ya que ésta no sólo nos permite experimentarla de una manera diferente sino, también, que se ha convertido en un modo de producción y composición dentro de la misma» (Théberge, 2006, p. 25). En consecuencia, reconocemos el potencial de los soportes tecnológicos de nuestra época y nos interesa promover músicos artistas profesionales que disputen dentro de la industria cultural los espacios de producción simbólica y desarrollen imágenes sonoras poéticas que nutran de nuevos sentidos a la sociedad. Conviene aclarar que reconocemos la tensión que hay entre las categorías de lo masivo y lo popular, por eso no las utilizamos como sinónimas, sino como nociones complementarias ya que muchas veces lo popular no es necesariamente masivo, ni todo lo masivo proviene del campo popular. Pero insistimos en que lo popular puede ser una producción artística masiva sin ninguna concesión en la elaboración de imágenes metafóricas.

De este modo, nos gusta pensar que nuestros estudiantes deben estar preparados para trabajar en todo tipo de propuestas, incluso para los medios masivos audiovisuales como la televisión, el cine, las series, los nuevos formatos en internet. Como ya se dijo, sostenemos que en lo industrial puede haber arte y que, por lo tanto, es posible trabajar para enriquecer los productos artísticos de la industria con propuestas que desplieguen imágenes poéticas, ${ }^{1}$ que tensionen lo dado, que cuestionen lo establecido. Por eso, en la cursada hacemos hincapié en prácticas con criterios profesionales e intervenciones colectivas, además de interdisciplinarias como, por ejemplo, el Programa de Tesis Colectivas² que ofrece la FBA. En el campo profesional, el trabajo en equipo que integra conocimientos de diferentes áreas para la realización de producciones artísticas es hoy una constante.

1 El siguiente párrafo amplía un poco más la noción de poética a la que nos referimos: «El arte es muchas cosas y significa, seguramente, tantas otras. Conjuga su visibilidad con sus zonas omitidas y tiende a desautomatizar y desnaturalizar la percepción volviéndola lenta, materializando rasgos de lo humano en un eje espaciotemporal propio que suspende el entorno físico. A esta cualidad, la de quebrar hábitos perceptuales la han llamado "poética", doble sistema de causalidad, símbolo, ya comentamos que los primeros formalistas la denominaban "trama"» (Belinche, 2017, p. 35).

2 Desde hace dos años la FBA ofrece el Programa de Tesis Colectivas que fomenta la graduación a término en todas las carreras, favorece el trabajo grupal-interdisciplinario, posibilita la producción de tesis con prácticas más cercanas al campo profesional y estimula presentaciones no convencionales en el ámbito académico. 
Además, la difusión a gran escala de la música ya no puede pensarse por fuera del ámbito de la escena o de la composición visual performática 0 diferida. En nuestra función docente, asumimos como propio el desafío de promover entre los tesistas estas formas de trabajo. Cada encuentro es una oportunidad para el intercambio con la intención de que el proceso de elaboración de la tesis de cada uno sea el resultado de una construcción del conjunto. Es decir, madurar las propias ideas al calor de las opiniones de los otros.

La etapa de selección del tema, del marco teórico o de los casos a analizar exige un esfuerzo consciente de interpretación. «La actividad interpretativa tiene raíces en la tradición hermenéutica, para la cual, todo proceso interpretativo es un intento de comprensión de la palabra ajena» (Eco, 2008, p. 298). De esta manera, Eco relaciona interpretoción y comprensión casi en una misma operación. Qué es lo que queda y qué dejo fuera del trabajo; qué autores, músicas, géneros elegir; en todo momento el acto interpretativo interviene y va formalizando el corpus de lo trabajado.

Además, la interpretación se convierte en uno de los factores clave al momento de cierre, en el análisis de todos los elementos que componen la tesis y la minuciosa elaboración de las conclusiones, ya que siempre es orientadora e intencional hacia la construcción de un determinado sentido. El peso de los argumentos a partir de marcos teóricos, la fluidez de las relaciones entre aspectos variados, el desarrollo de los núcleos temáticos, la elaboración de las producciones musicales y la síntesis de todo el recorrido serán factores indispensables al momento de la evaluación.

\section{PERO ENTONCES, ¿CÓMO SE HACE UNA TESIS?}

Estrategias organizativas y de búsqueda, procedimientos metodológicos, intervenciones individuales y colectivas, análisis, interpretaciones y orientaciones sobre las propias producciones musicales y escritas, son diferentes herramientas que integramos plenamente durante toda la cursada, para hacer emerger lo que crepita y abrir camino a la sospecha de lo indecible; para asir en un objeto elaborado con pasión, el destello de lo imaginado.

Por eso, entendemos que hacer una Tesis representa un esfuerzo en el horizonte de lo posible para un estudiante del último año de la carrera de Música Popular de la FBA. Es transitar el tramo final de un camino, un camino que hay que reinventar relacionando las huellas que otros dejaron. Un camino que presenta dificultades y avances en partes proporcionales. Un camino cuya experiencia temporal consiste en aprender a demorarse en los intersticios de las imágenes sonoras para hacer presente el pasado de lo poéticamente imaginado. Un camino que se desanda para adelante, en el que se van construyendo certezas, posiciones y aproximaciones en lo profundo de un océano de incertidumbres. Es decir, una mirada propia 
sobre el mundo ahora, una posición tomada en el mientras tanto, una manera de sonar y escuchar; en definitiva, una particular «invención musical».

\section{REFERENCIAS}

Belinche, D. (2011). Arte, poética y educación. La Plata, Argentina: Facultad de Bellas Artes, Universidad Nacional de La Plata.

Belinche, D. (2017). Diez formas de arruinar uno close. La Plata, Argentina: Malisia editorial. Facultad de Bellas Artes, Universidad Nacional de La Plata. Benassi, V. y Schinca, J. (2017). Taller de iniciación al canto. La voz como instrumento básico en las consignas de las clases con ingresantes. Ponencia presentada en el $1 .{ }^{\circ}$ Congreso Internacional de Enseñanza y Producción de las Artes en América Latina. Facultad de Bellas Artes de la Universidad Nacional de La Plata, La Plata, Argentina. Recuperado de http://www.fba. unlp.edu.ar/ciepaal/wp-content/uploads/2017/10/5.2.-TALLER-DE-INICIACI0\%CC\%81N-AL-CANTO.-LA-VOZ-COMO-INSTRUMENTO-BA\%CC\%81SICO-EN-LAS-CONSIGNAS-DE-LAS-CLASES-CON-INGRESANTES..pdf

Eco, U. [1997] (2016). Como se hace una tesis. Ciudad de México, México: Gedisa.

Eco, U. (2008). Decir casi lo mismo. Experiencias de traducción. Montevideo, Uruguay: Lumen, editorial Sudamericana.

Etkin, M. y Villanueva, C. (Trads.) (2013). Entrevisto a Edward T. Cone. La Plata, Argentina: Facultad de Bellas Artes, Universidad Nacional de La Plata. Gelman, J. (2001). Saber. En Valer la peno. Buenos Aires, Argentina: Seix Barral.

Kozak, C. (2008). El tiempo y el arte. En G. Indij (Comp.), Sobre el tiempo (pp. 187-193). Buenos Aires, Argentina: La marca editora.

Kusch, R. [1976] (2007). Geocultura del hombre americano. Obras completos. Tomo III. Rosario, Argentina: Editorial Fundación Ross.

Mendoza, A.y Schinca, J. (2017) Mi alma no la atraparás. III Jornadas Estudiantiles de Investigación en Disciplinas Artísticas y Proyectuales. Facultad de Bellas Artes de la Universidad Nacional de La Plata, La Plata, Argentina. Recuperado de http://sedici.unlp.edu.ar/bitstream/handle/10915/66501/Documento_completo.pdf-PDFA.pdf?sequence=18isAllowed=y

Romero, P. (2007). Un conocimiento por el montaje, una entrevista con George Didi-Huberman. Minervo. Revisto del Círculo de Bellas Artes de Modrid, IV (5) Recuperado de http://www.circulobellasartes.com/revistaminerva/articulo.php?id=141

Samaja, J. (2006). El proceso de la ciencio. Recuperado de http://www. biblioteca.org.ar/libros/131841.pdf

Schinca, J. (2013). Jidap 2013 FBA UNLP 1era parte [Archivo de video]. Disponible en https://www.youtube.com/watch?v=075HFvsyGsc\&t=308s Théberge, P. (2006). La otra historia del rock. Barcelona, España: Robinbook. 